\title{
Human-Computer Interaction Education and Diversity
}

\author{
Tom Gross \\ Human-Computer Interaction Group, University of Bamberg, Germany \\ tom.gross@uni-bamberg.de
}

\begin{abstract}
Human-Computer Interaction has evolved into an established field of teaching and research. Its multidisciplinary and cross-continental roots combined with its broad scope and multiplicity of paradigms, methods, tools, and application areas have led to a huge diversity. In the community there are currently debates about the pros and cons of this diversity and some voices claim for unifying theory and practice and standardising teaching curricula. In this paper I discuss HCI education, and analyse the past, present, and future of $\mathrm{HCI}$ in order to derive implications for HCI education.
\end{abstract}

Keywords: Human-Computer Interaction, Diversity.

\section{Introduction}

Human-Computer Interaction (HCI) has over the last decades evolved into an established field of teaching and research that marks an important paradigm shift. Wegner [31, p. 81] writes: 'interactive systems are more powerful problem-solving engines than algorithms.'. Yet, the field of HCI is multidisciplinary, which to some authors seem challenging. Grudin [14, p. 59] writes: 'different views of humancomputer interaction are presented ... and differences will remain'. Researchers and teachers in HCI have reacted to multidisciplinarity by elaborating on shared understandings in HCI education. Claims for unification have been raised. For instance, Churchill et al. have compiled an informative report on 'Teaching and Learning Human-Computer Interaction: Past, Present, and Future' [5]. It analyses one of the big challenges of teaching HCI: the rapid evolution of the field. The authors write: 'during the past 15 years, the speed of change has been particularly dramatic' and they continue 'in response to these technological changes, user populations have diversified and grown' [5, p. 44]. The authors point out that in their interviews 'a common refrain we hear is "We need a mission statement or a value proposition that people can hang their hats on." Our survey respondents and interviewees call for some form of unity or consensus; there is a desire for "a unified theoretical perspective" and "a common curriculum.".

In this paper I examine the field of $\mathrm{HCI}$ and $\mathrm{HCI}$ education with respect to their diversity. For this purpose, I analyse HCI education today and study HCI curricula and books. I then characterise trends in HCI. I draw conclusions for HCI education. Finally, I summarise the paper. 


\section{HCI Education Today}

HCI education needs to reflect multidisciplinary origins in computer and human science and beyond, respect the complexity in theories, methods, and tools, for the design, implementation, and evaluation of interactive systems. Several authors have emphasised this multidisciplinary and have also identified disciplines and areas of $\mathrm{HCI}$ that are relevant for $\mathrm{HCI}$ research and teaching. Carroll $[4, \mathrm{p}$. 1] emphasises the combination of the human and the computer side: 'human-computer interaction (HCI) lies at the intersection between the social and behavioural sciences on the one hand, and computer and information technology on the other.' Yet, to add even more complexity, HCI should not only be seen from a research perspective, but also an engineering and design perspective, and they are rather distinct. MacKenzie [21, p. 126f] points out: 'there are many ways to distinguish research from engineering and design. ... Engineers and designers are in the business of building things. ... Research tends to be narrowly focused. Small ideas are conceived of, prototyped, tested, then advanced or discarded.'

Teaching HCI from the perspective of designing artefacts that are easy to understand and use, sometimes seemed quite easy. There the focus was primarily on the artefacts that are designed and their capability to communicated their handling to users (e.g., for doors it should be immediately clear if users need to push or pull). For instance, Norman [22, p. 188f] suggested 'seven principles for transforming difficult tasks into simple ones' such as: 'simplify the structure of tasks'. Beyond the artefact, design is always about the users who interact with the artefact. In his later publications Norman points out that [23, p. 8]: 'in the 1980s, in writing The Design of Everyday Things, I didn't take emotions into account. I addressed utility and usability, function and form, all in a logical, dispassionate way.'. Norman in this book identifies three different aspects of design [23, p. 5f]: 'visceral design concerns itself with appearances. ... behavioural design has to do with the pleasure and effectiveness of use. ... finally, reflective design considers the rationalisation and intellectualisation of a product.'. Draper and Norman [8, p. 1] already in the 1980ies identified the need to deal with humans and computers, but also interaction: 'to understand successful design requires an understanding of the technology, the person, and their mutual interaction.'.

Since then, the field of HCI has grown considerably and with that also the body of knowledge of potential interest for students of HCI. Carroll [4, p. 6] writes that in the 1980s 'it was reasonable to expect HCI professionals, particularly researchers, to have a fairly comprehensive understanding of the concepts and methods in use. Today, there are too many theories, too many methods, too many application domains, too many systems.'. Subsequently I analyse HCI curricula and HCI reference books and textbooks with respect to their contents, and structure. I will particularly reflect the disciplines and areas identified in the quotes above: the role of computer and information technology versus social and behavioural sciences; the role of research versus design and engineering; the role of users' goals and tasks; the role of visceral, behavioural, and reflective aspects; as well as the role of theories and methods versus application domains and systems. 


\subsection{HCI Curricula}

In this section I introduce three curricular suggestions for teaching HCI: the Curricula for Human-Computer Interaction of the Association of Computing Machinery's Special Interest Group on Computer-Human Interaction of (ACM SIGCHI), the Computing Curricula 2001 - Computer Science of the Joint Task Force on Computing Curricula of the Institute of Electrical and Electronics Engineers Computer Society (IEEE CS) and the Association for Computing Machinery (ACM), and the Recommendations for Software Ergonomics Education of the German Informatics Society (Gesellschaft für Informatik e.V., GI).

In the Curricula for Human-Computer Interaction Hewitt et al. [17] list the following 'contents of HCI': the nature of HCI: meta-models, and models for HCI; use and context of computers: human social organisation and work; application areas; human-machine fit and adaptation; human characteristics: human information processing; language, communication, interaction; ergonomics: computer system and interface architecture; input and output devices; dialogue techniques; dialogue genre; computer graphics; dialogue architecture; development process: design approaches; implementation techniques; evaluation techniques; example systems and case studies; as well as project presentations and examinations. The authors suggest that this content can be tailored to different courses. For instance, in a computer science department the content could be presented in two courses of 14 weeks and 42 contact hours each with a broad and even distribution of topics in the first course, and a special focus on human social organisation and work; human information processing; and language, communication, and interaction in the second. While the nature of the first course is practical, the one of the second is scientific. Alternatively, a psychology, human factors, or industrial engineering department could offer a course on the psychology of HCI with 14 weeks and 42 contact hours emphasising the theoretical and empirical foundation of the above contents. This course could offer a broad overview of all topics. Finally, in an information systems department a course on human aspects of information systems with also 14 weeks and 42 contact hours could deepen a non-technical understanding of user needs and system capabilities for users and managers.

In the case of fewer resources for HCI, Hewitt et al. suggest to include HCI courses 'into all technology-oriented courses'. And the authors claim that 'iterative design, usability testing, and user productivity be at least mentioned as issues of concern in courses at all levels'. While these suggestions are two decades old and details have changed, the content is from a conceptual perspective still relevant. The Computing Curricula [18] outlines important changes that influence the computer science discipline. It names technical changes through technological advancements in areas such as the World-Wide Web, networking technologies, graphics and multimedia, embedded systems, but also HCI; and cultural changes in the 'cultural and sociological context' such as changes in pedagogy enabled by new technologies, growth of computing through the world, but also a broadening of the discipline. This curriculum lists the computer science body of knowledge with 14 main areas, one of them being HCI. Within HCI the curriculum names the two core topics: foundations 
of HCI; and building a simple graphical user interface. It lists six further topics: human-centred software evaluation; human-centred software development; graphical user-interface design; graphical user-interface programming; HCI aspects of multimedia systems; and HCI aspects of collaboration and communication. Beyond these topics the curriculum also suggests various advanced courses 'whose content is substantially beyond the material of the core'. For HCI the following advanced courses are suggested: human-centred design and evaluation; graphical user interfaces; multimedia systems development; interactive systems development; and computer-supported cooperative work.

The Recommendations for Software Ergonomics Education [20] names the following nine desired qualifications of HCI experts: understanding of software development as a part of work and organisation design; ability to recognise the requirements of work situations and to take these into account in system design; ability to analyse and describe work and tasks; ability to determine an appropriate human-computer functional separation; ability to design $\mathrm{HCI}$; ability to judge software products with respect to their functionality for task-adequate functionality and user-adequate handling; ability to organise the system development process while taking user requirements into account; ability to organise the cooperation process between users and developers; and ability to introduce systems in such a way that hindrances or pressures for those affected are kept to a minimum and that no-one's rights are reduced. The curriculum recommends an introduction with softwareergonomic design of human-computer systems; theoretical, psychological, ergonomic basics; and design with design of computer-supported work systems, dialogue systems, input and output design, ergonomics-oriented system development, system introduction and use, and system evaluation.

A later curriculum of the GI has updates compared to the original recommendation, but is only availably in German [29]. Being published 13 years later, it emphasises differences compared to the original recommendation with respect to application areas of HCI (i.e., e-business, e-learning, e-government, edutainment, infotainment, and games), with respect to new forms of devices and interaction (i.e., mobile devices, mobile phones, wearable), and with respect to new usability engineering methods. The suggested basic module for HCI should have a minimum of 15 weeks of two weekly hours. The contents includes three blocks: introduction with chapters on human, task, software, on the development of software-ergonomics, and on standards and legal foundation; basics of HCI with chapters on human information processing and activities, on input and output devices, on interaction techniques, and work and task design; and user-centred development processes with chapters on usercentred process models, on analysis of needs and requirements, on specification and prototyping, and on evaluation. Analysing these curricula it becomes clear that the core topics of HCI education have witnessed some evolution, but at the same time they have kept a balance between technical (computer and information technology) and human (social and behavioural sciences). Users' goals and tasks as well as theories and methods play a major role. They have a stronger focus on research and engineering over design, and visceral, behavioural, and reflective aspects play a minor role. Application domains and systems are primarily addressed in additional courses beyond the core topics. 


\subsection{HCI Reference Books and Textbooks}

Books for students of HCI have proliferated recently. Reference books have been followed by textbooks for various levels of teaching and studying HCI. Comprehensive reference books with great collections of publications on HCI topics have early been published in [16] and in [1], and later in [25]. The two most prominent early and comprehensive reference books are the Handbook of HumanComputer Interaction by Helander et al. with over 1500 pages and the Readings in Human-Computer Interaction by Baecker et al. with over 900 pages. Both have been updated to a second edition [cf. 1, 16], but have not further. While both are still of great use as reference books, they do not provide details on teaching or studying HCI; in fact, Baecker et al. suggest to follow the ACM SIGCHI Curricula and explain how their book covers topics of the four courses described above (two for computer science, one for psychology, one for management information systems).

The reference book by Sears and Jacko on The Human-Computer Interaction Handbook has been updated to a second edition [25] and is a follow up of the two reference books above. In his foreword Shneiderman suggests the book to readers with various backgrounds $[25, \mathrm{p}$. xix]: 'practitioners ... newcomers to $\mathrm{HCI} \ldots$ outsiders ... visionary readers'. The parts of the book are: humans, computers, designing human-computer interactions, application and domain specific design, designing for diversity, development process, and managing $\mathrm{HCI}$ and emerging issues. So, a correspondence to the above curricula is obvious (esp. with respect to the later curriculum of the GI mentioned above). Textbooks homogeneously present HCI material, often in the form of monographs, to teachers and students of HCI. There are introductory textbooks that either provide a broad and general overview of the field [e.g., 24], or primarily focus on methods and the doing [e.g., 28], or primarily focus on basic concepts of HCI [e.g., 7]. Intermediate level textbooks aim at combining breadth and depth of these matters [e.g., 2]. Advanced books provide advanced-level material [e.g., 4].

The introductory textbook entitled Interaction Design by Preece et al. [24] provides an up-to-date basic introduction to HCI. It is in its 3rd edition and can be used by undergraduate students and beyond. It is a balanced combination of traditional HCI topics (e.g., understanding and conceptualising interaction, cognitive aspects) and current topics (e.g., social interaction, emotional interaction) as well as of theoretical concepts (e.g., interfaces, evaluation studies) and practical methods (e.g., data gathering, data analysis). Stone et al.'s textbook on User Interface Design and Evaluation [28] has a focus is on practical and professional skills, knowledge and understanding, and cognitive skills rather than on history and broad theory of HCI. The textbook Human-Computer Interaction by Dix et al. is-like the book by Preece et al.-well balanced, but at the same time 'is also rooted in strong principles and models' [7, p. xix]. It provides four parts: part one with chapters on foundations (i.e., the human, the computer, the interaction, paradigms) and part two with chapters on the design process (i.e., interaction design basics, HCI in the software process, design rules, implementation support, evaluation techniques, universal design, user support). The next part goes has chapters on models and theories (i.e., cognitive 
models, socio-organisational issues and stakeholder requirements, communication and collaboration models, task analysis, dialogue notations and design, models of the system, modelling rich interaction). Finally, despite the fact that this 3 rd edition was already published in 2004 a fourth part has chapters with recent trends in HCI (i.e., groupware, ubiquitous computing and augmented realities, hypertext, multimedia and the World-Wide Web).

The intermediate textbook entitled Designing Interactive Systems by Benyon et al. [2] does not only provide a good combination of $\mathrm{HCI}$ in the parts: essential interactive systems design, people and technologies, activities and contexts of interactive systems design, psychological foundations for interactive systems design, techniques for interactive systems design and evaluation as well as information spaces, and computer-supported cooperative working, but also contributes recommendations on how to teach HCI. Through permutations of chapters several courses can be configured, some examples of which are, with 15 credits each: introduction to HCI; interaction design; user-centred design; future and emerging issues in HCI; advanced interactive systems design; designing for cooperation; web design; psychological foundations of HCI. This is possible, because the textbook not only contains traditional HCI knowledge, but also more recent lessons on methods and techniques (e.g., contextual design) as well as on information spaces (e.g., information architecture, information design, navigation of information space, agent-based interaction, ubiquitous computing and distributed information) and computersupported cooperative work (e.g., supporting communication, understanding cooperative working, technology to support cooperation).

The advanced-level book on HCI Models, Theories, and Frameworks: Towards a Multidisciplinary Science edited by Carroll [4] is a profound presentation of the theoretical and scientific basis of HCI and is used for teaching higher level students. It provides a deep insight into HCI with the following chapters: applied perception; behavioural models for HCI; information processing and skilled behaviour; notational systems; users' mental models; exploring and finding information; distributed cognition; cognitive work analysis; common ground in electronically mediated communication; activity theory; applying social psychological theory to the problems of group work; studies of work in HCI; computational formalisms and theory; and design rational as theory. There are more books available, but those here constitute prominent representatives of different complexity. They show that the topics of the curricula are covered, but also new topics have been added. Both human and technical factors are presented, yet for most books human factors are more detailed than technical factors. This is due to the fact that most books are designed to complement other courses, mainly computer science courses that already cover technological factors in great detail. Visceral, behavioural, and reflective aspects play an increasingly important role, especially in more recent books. And overall, theories and models are included as much as application domains and systems. Research and engineering are covered to a great extent, and design is covered with knowledge on designing interactive systems (esp. about users and their context) as well as methods to develop prototypes. Design from the perspective of aesthetics and artistic skills and craftsmanship is not part of standard HCI literature. Yet, books from disciplines overlapping with or at the fringe of HCI have been published that provide great introductions to these matters for readers without artistic knowledge and skills [e.g., 9]. 


\section{Trends in $\mathrm{HCI}$}

In the above section I have already pointed at some developments in HCI curricula and books. In this section I look more closely to such developments in HCI from the past to the present in order to identify trends in $\mathrm{HCI}$ into the future.

\subsection{The Emergence of $\mathrm{HCI}$}

The emergence and evolution of HCI was very often leveraged by the emergence of new technologies. Benyon et al. bring this to the point [2, p. ixx]:

In the early 1990s the 'world wide' Web appeared, opening up website design as a new area. ... By the late 1990s mobile phones had become a fashion statement for many people; style was as important as function. ... User interfaces became tangible, graspable and immediate and software systems had to be engaging as well as functional. ... All this has brought us to where we are today: a dynamic mix of ideas, approaches and technologies being used ... in different contexts.

As has been pointed out above HCI has a human and a technical side. Carroll [4, p. 2] explains: 'HCI was originally a joining of software engineering and humanfactors engineering.'. Both sides-the human and the technological-are evolving. Yet, as Grudin writes, the pace of development can be different [15, p. 2]: 'aspects of the human side of HCI change more slowly if at all. Much of what was learned about perceptual, cognitive, social, and emotional processes in interacting with older technologies applies to emerging technologies'. Looking at the evolution of the technological factors it is interesting to start at the origins. MacKenzie [21] characterises a trajectory from the early seminal work of Vannevar Bush [3] who claimed that we should build systems that support the creation, maintenance, and following of associations between documents-just like hypertext systems and links in the World-Wide Web today. Another milestone was Ivan Sutherland's SketchPad, which provided interactive graphics that users could grasp and move. It was already published in 1963, and reprinted in 2003 [30]. And, as a last example, Doulas Engelbarts and William English's [10] NLS system was presented and live demonstrated in 1968 and offered users an interactive text processor application to write texts, including figures and tables, and featured an integrated audio and video conferencing tool to communicate with remote colleagues. Part of the NLS was the computer mouse-as we know it today-that the authors invented at the same time. The technical progress then continued, and can be characterised with an evolution from single-user systems that were based on graphical user interfaces and windows, mice, menus, and pointing devices; to cooperative systems that supported the communication and collaboration over distance; to ubiquitous computing with technology to sense users' presence and activities, infer their needs, and adapt the environment accordingly; and finally to ambient intelligence that 'adapts to the presence of people and objects and assists users smartly while preserving security and privacy' [12, p. 274]. While these technologies follow each other chronologically, they do not necessarily replace, but rather complement each other, and have been used in parallel until today (e.g., most users still use windows-based systems such as Mac OS X or Windows). 
With respect to human factors used in HCI Draper and Norman point out that technology is important, yet a focus on users and their needs should prevail [8, p. 2f]: 'the emphasis is on people, rather than technology, although the powers and limits of contemporary machines are considered in order to know how to take that next step from today's limited machines toward more user-centred ones.'. And technological progress does not happen in isolation of the human aspects and methods in HCI. Gross analysed the consequences of the evolution of technology on the process and methods to design, implement, and evaluate the respective technology [13]. According to the author, for instance, the waterfall model was adequate for the time when mainframe hardware was dominant and development cycles very long. Later, with a stronger focus on users and the advent of HCI, more iterative models were used. And, more recently, human-centred models focus on users, tasks, contexts, and ambient adaptations and their iterative design, development, and evaluation. Carroll emphasises the evolution and diversification of the human factors and methods in HCI in his book in a chapter entitled Let 100 Flowers Blossom with a 'differentiation within the original cognitive-science community of HCI' [4, p. 4f]. In the 1980s computer technology was new to most users and so the focus was on 'learning and comprehension problems of novice users ... It addressed issues such as abductive reasoning, learning by exploration, external representations, and the development of analogies and mental models.'. Furthermore, at that time cognitive science also became more diverse and multidisciplinary per se. As Carroll [4, p. 4f] puts it:

Social psychologists, anthropologists, and sociologists entered the cognitivescience discourse, sometimes taking HCI as their empirical touchstone. Suchman's study of photocopier use described a variety of usability problems with advanced photocopier-user interfaces. She considered the interaction between the person and the machine as a sort of conversation that frequently fails because the participants do not understand one another.

And another driving force for diversification was the internationalisation of HCI, which according to Carroll [4, p. 4f] was 'facilitated by several International Federation for Information Processing (IFIP) conferences held in Europe, and by initiatives within major computer companies'. Combining technological and human factors into an overall focus on HCI as a discipline Shackel published a seminal paper in 1997 with a reprint in 2009 [26], where he characterises the technological, human, and methodological progress, but also the evolution of the field with research centres, conferences and journals, and a body of knowledge that has been growing rapidly. In a similar vein Grudin [15] characterised the overall evolution of HCI, as well as human factors and ergonomics, and information systems. He-like Carroll-also points out the increasing diversity, which in his opinion is related to the divergence of $\mathrm{HCI}$ and human factors.

Overall, HCI has evolved, yet many seminal works and theories, and models do not outdate. For instance, Erickson and McDonald [11, p. 3] write that there is 'valuable older work fading from our discipline's working memory. We are interested in bringing back that work in a way that reflects the diversity of the field's influences, and the idiosyncrasies of the individuals who constitute the discipline.'. 


\subsection{The Present and the Future of HCI}

$\mathrm{HCI}$ as a field has been developing at great speed and is integrating new disciplines as well as by expanding into other disciplines. Sears and Jacko are positive about this development and write [25, p. xxi]: 'HCI is no longer just an area of specialisation within more traditional academic disciplines, but has developed such that both undergraduate and graduate degrees are available that focus explicitly on the subject.'. In an article with the title Is HCI Homeless? Grudin is less optimistic. He discusses distinguishes HCI from human factors and ergonomics, and from information systems along various dimensions: for instance, discretionary use of technology in HCI versus non-discretionary use of technology in human factors and ergonomics as well as in information systems.

Liu et al. [19] analysed all papers of the ACM CHI conference of two decades with a total of 3152 papers and 16035 keywords and did a co-word analysis. The first decade of 1994 to 2003 - compared to the second of 2004 to 2013 - had a fixed focus. In the second decade the field and the number of publications had grown tremendously (i.e., 702 vs. 2450 papers) and spread into directions such as mobile and social interaction, with novel scenarios such as crowdsourcing and privacy in the online world. The authors identify major research themes for the first decade such as computer-supported cooperative work, interaction design, computer-mediated communication; World-Wide Web, empirical study, email; ubiquitous computing, augmented reality, tangible user interface; etc. For the second decade similarities and differences in the most prominent topics could be identified, with topics such as: mobile phone, sustainability, ethnography; ubiquitous computing, privacy, mobile; visualisation, collaboration, user interface; etc. Looking closer into recent trends of the second decade emerging changes can be identified that give an impression on how the publication topics of the ACM CHI conference might evolve in the future. For instance, sustainability and ethnography are popular topics, and education, learning, communication, and awareness are backbone topics, and according to the authors need special attention since they are vital for the field. The authors conclude that HCI is a diverse and dynamic field with a fast pace of technological development, and a slower but still important pace of theories and models in HCI. This corroborates above findings. Topics emerge, topics merge, topics interact with each other, and the overall network of keywords has been polycentric. Thus the HCI community had been and should remain adaptive in the future.

So, over the last 70+ years HCI has witnessed a development with technological progress, conceptual insight, and new theories and methods. The emergence of the field can be characterised by gigantic monolithic projects with project teams of hundreds of members. Over the last two decades the growth and diversification has increased-especially in the last decade. There is agreement among authors that HCI has definitely become bigger and more diverse, but there are different opinions whether this development is positive or negative and whether it is possible to stop it or even turn it back by unifying research strands. Looking at the very detailed analysis of Liu et al. it seems that growth and diversification in the flagship conference of the field - the ACM CHI conference — and beyond is positive and irreversible. 


\section{Lessons Learned for HCI Education}

HCI is distinct from other fields such as computer and information science and software engineering, despite the fact that it emerged from such fields. This is partly due to the fact that users with their goals and tasks, needs and requirements, tools and contexts will always remain in the centre of the focus of HCI, but not necessarily the focus of other related disciplines. Because of the growth, diversification, and uniqueness new HCI study programmes only partly fit into old structures and are therefore in many institutions separate from existing programmes. Shneiderman writes [27, p. 71]:

Universities ... sprout successful new units such as the Human-Computer Interaction Institute at Carnegie Mellon University or the Media Lab at the Massachusetts Institute of Technology. Interdisciplinary groups, such as those at Stanford University or the University of Maryland, bring together faculty and students from multiple departments.

Those universities that early on embarked on teaching HCI in traditional face-toface classroom courses are now also the ones that early produced material that can be taught in online courses with remote students. In recent years, Massive Open Online Courses (MOOCs) have become popular, also in HCI [6]. Despite the changes of technological and human factors as well as theories and models, it is important for HCI education to not only run after the most recent trends, but also stay focused and also teach practical skills. HCI thinking emerges through a balance of theoretical knowledge and practical experience. Shneiderman points out [27, p. 112]: 'memorable educational experiences ... enrich students with increased knowledge and skills, provide them with a satisfying sense of accomplishment.'.

And, although the field of HCI is growing fast and becoming increasingly diverse, it is still important to keep the overall picture, which has over centuries been a virtue that has never changed. Shneiderman analysed Renaissance thinking and takes Leonardo da Vinci as a role model and writes [27, p. 2]:

This modern Renaissance would unify thinking about technology by promoting multidisciplinary education and a sympathy for diversity. ... Leonardo integrated engineering with human values. ... Leonardo-like thinking could help users and technology developers to envision the next generation of information and communication technologies.

So, it is quite likely that in the future HCI will further grow and get rather get more diverse, and so will HCI education with respect to both contents and formats of teaching. Recommendations for curricula can give guidance and help avoiding misunderstandings, frame expectations with respect to qualifications of students, and provide a shared reference and orientation. At the same time it is a great strength of HCI that it is diverse in paradigms, theories, principles, methods, tools and conceptual and technological results. HCI education should reflect that and adapt the structure, contents, and format to the respective situation and needs. Since any HCI education, no matter how small it may be, is better than no HCI education, it is also important to scale down HCI education. Scaling up education and providing complete study programmes in the form of Bachelor, Master, or $\mathrm{PhD}$ programmes is possible, since over the decades the body of knowledge developed have become so vast. 


\section{Conclusions}

$\mathrm{HCI}$ has over the last decades matured to an exciting field of research and teaching. The community is growing, the number and size of scientific and industrial venues is growing, and the body of knowledge is almost exploding. HCI should always have an early focus on users, tasks, and their contexts. Since user populations, tasks, contexts and application scenarios are getting increasingly divers, it is adequate that also the means to deal with them-in terms of theory, paradigms, methods, tools-are also expanding their range. In this paper I have analysed HCI education today. I have characterised the past, present, and future of the field of HCI. I have discussed the consequences for teaching HCI face-to-face and online. Overall, I am very optimistic that the growth and diversification of $\mathrm{HCI}$ research and education is positive for the development of the field into the future. As has been pointed out in the introduction at the very beginning of this paper with the quote of Wegner-in his words of the title of the quoted publication 'interaction is more powerful than algorithms. Powerful and complex interaction should be handled with diverse approaches.

Acknowledgments. I would like to thank all colleagues whom I had invaluable discussions; especially my colleagues from the TC.13 on Human-Computer Interaction of the International Federation for Information Processing IFIP, and from the Steering Committee of Human-Computer Interaction and of Computer-Supported Cooperative Work of the Germany Informatics Society (Gesellschaft für Informatik, GI).

\section{References}

1. Baecker, R.M., Grudin, J., Buxton, W.A.S., Greenberg, S. (eds.): Readings in HumanComputer Interaction, 2nd edn. Morgan Kaufmann Publishers, San Francisco (1995)

2. Benyon, D., Turner, P., Turner, S.: Designing Interactive Systems. Addison-Wesley, Reading (2005)

3. Bush, V.: As we think. The Atlantic Monthly 176(1), 101-108 (1945)

4. Carroll, J.M. (ed.): HCI Models, Theories, and Frameworks. The Morgan Kaufmann Series in Interactive Technologies. Morgan Kaufmann Publishers, San Mateo (2003)

5. Churchill, E.F., Bowser, A., Preece, J.: Teaching and Learning Human-Computer Interaction: Past, Present, and Future. ACM Interactions, 44-53 (March/April 2013)

6. Cooper, S., Sahami, M.: Education - Reflections on Stanford's MOOCs. Communications of the ACM 56(2), 28-30 (2013)

7. Dix, A., Finlay, J., Abowd, G.D., Beale, R.: Human-Computer Interaction. Pearson, Englewood Cliffs (2004)

8. Draper, S.W., Norman, D.A.: Introduction. In: Norman, D.A., Draper, S.W. (eds.) User Centred System Design, pp. 1-5. Lawrence Erlbaum, Hillsdale (1986)

9. Edwards, B.: The New Drawing on the Right Side of the Brain: A Course in Enhancing Creativity and Artistic Confidence. Penguin Putnam Inc., N.Y. (1999)

10. Engelbart, D., English, W.K.: A Research Centre for Augmenting Human Intellect. In: Proc. of the Fall Joint Computing Conference - FJCC 1968, Montvale, NY, pp. 395-410. AFIPS Press, Washington (December 1968) 
11. Erickson, T., McDonald, D.W. (eds.): HCI Remixed. MIT Press, Cambridge (2008)

12. Gross, T.: Cooperative Ambient Intelligence: Towards Autonomous and Adaptive Cooperative Ubiquitous Environments. Int. J. of Autonomous and Adaptive Communications Systems (IJAACS) 1(2), 270-278 (2008)

13. Gross, T.: Towards a New Human-Centred Computing Methodology for Cooperative Ambient Intelligence. J. of Ambient Intelligence and Humanised Computing (JAIHC) 1(1), 31-42 (2010)

14. Grudin, J.: Is HCI Homeless? In Search of Inter-Disciplinary Status. ACM Interactions 13(1), 54-59 (2006)

15. Grudin, J.: A Moving Target: The Evolution of HCI. In: Sears, A., Jacko, J.A. (eds.) Human-Computer Interaction Handbook, 2nd edn., pp. 1-24. Lawrence Erlbaum, Hillsdale (2008)

16. Helander, M.G., Landauer, T.K., Prabhu, P.V.: Handbook of Human-Computer Interaction. Elsevier, Amsterdam (1997)

17. Hewett, T.T., Baecker, R.M., Card, S.K., Carey, T., Gasen, J., Mantei, M.M., Perlman, G., Strong, G., Verplank, W.: ACM SIGCHI Curricula for Human-Computer Interaction. ACM (1992), http: / /old.sigchi .org/cdg/index.html (accessed January 31, 2014)

18. IEEE \& ACM. Computer Curricula 2001. IEEE CS \& ACM (2001), http://www . acm.org/education/curric_vols/cc2001.pdf (accessed January 31, 2014)

19. Liu, Y., Goncalves, J., Ferreira, D., Xiao, B., Hosio, S., Kostakos, V.: CHI 1994-2013: Mapping Two Decades of Intellectual Progress through Co-Word Analysis. In: Proc. of the Conference on Human Factors in Computing Systems - CHI 2014 (to appear, 2014)

20. Maass, S., Ackermann, D., Dzida, W., Gorny, P., Oberquelle, H., Roediger, K.-H., Rupietta, W., Streitz, N.: Recommendations for Software Ergonomics Education. GI e.V. (1994), http: / /www-cg-hci.informatik. uni-oldenburg. de/GIRecommendations / (accessed January 31, 2014)

21. MacKenzie, I.S.: Human-Computer Interaction. Morgan Kaufmann Publishers, San Mateo (2013)

22. Norman, D.A.: The Design of Everyday Things, Doubleday/Currency, N.Y. (1988)

23. Norman, D.A.: Emotional Design. Basic Books, N.Y. (2004)

24. Preece, J., Rogers, Y., Sharp, H.: Interaction Design. Wiley, N.Y. (2011)

25. Sears, A., Jacko, J.A. (eds.): Human-Computer Interaction Handbook, 2nd edn. Lawrence Erlbaum, Hillsdale (2008)

26. Shackel, B.: Human-Computer Interaction - Whence and Whither? Interacting with Computers 21, 353-366 (2009)

27. Shneiderman, B.: Leonardo's Laptop. MIT Press, Cambridge (2002)

28. Stone, D., Jarrett, C., Woodroffe, M., Minocha, S.: User Interface Design and Evaluation. Morgan Kaufmann Publishers, San Francisco (2005)

29. Strauss, F., Beck, A., Dahm, M., Hamborg, K.-C., Heers, R., Heinecke, A.M.: Curriculum for a Base Module for Human-Computer Interaction. GI e.V. (2006), http: / / www . gi ev.de/fileadmin/redaktion/empfehlungen/GI-Empfehlung_MCIBasismodul2006.pdf (accessed February 5, 2014)

30. Sutherland, I.E.: Sketchpad: A Man-Machine Graphical Communication System (2003), https : / /design. osu. edu/carlson/history/PDFs /UCAM-CL-TR574.pdf (accessed October 10, 2011)

31. Wegner, P.: Why Interaction Is More Powerful Than Algorithms. Communications of the ACM 40(5), 81-91 (1997) 